\title{
An Analysis of Early Marriage Determinant and Its Impact on Women's Reproduction Health
}

\author{
${\text { Rohmayanti }{ }^{*} \text {, Reni Mareta }}^{1}$ \\ ${ }^{1}$ Department of Nursing, Universitas Muhammadiyah Magelang, Magelang, Indonesia \\ *Corresponding author. Email: rohmayanti@ummgl.ac.id
}

\begin{abstract}
Early marriage is a world problem related to various health and social consequences for teenage girls. Designing effective health interventions to overcome early marriage needs to apply a community-based approach. However, it has not received sufficient attention from policy makers and health researchers in Indonesia. This study aims to explore the determinants of early marriage from the perspective of married women and find out the impact on reproductive health. This study is a qualitative descriptive study with a phenomenological approach. The research was conducted in Ketundan, Banyusidi and Petung Village, Pakis District, Magelang Regency. The sampling method used selected respondents who fulfil the requirements using the snowball technique. The data was collected through face-to-face and semi-structured interviews, and analysed using a conventional content analysis approach. This study indicated that there were two major themes in this study, namely 1) causal factors of early marriage in five categories of determinants of early marriage are economy, education, social-culture, internal factors, and parents' roles; 2) the impact of early marriage on women's reproductive health with three categories, namely: pregnancy, childbirth, and the puerperium. The result obtained by the research was that the practice of early marriage in the Pakis subdistrict constituted by major factor, which was the economic factor that has a direct impact on women's reproductive health, especially in the process of pregnancy, childbirth until after birth that affect the degree of health.
\end{abstract}

Keywords: early marriage determinant, women's reproduction, health

\section{INTRODUCTION}

Teen is a critical age for girls throughout the world. For many girls in developing countries, the start of puberty marks a time of increased feasibility of early marriage and an entry into sexual life [1]. There are various factors that contribute to the existence of early marriage, including the dominance of men, ignorance of parents, and the social forces [2]. Early marriage is very likely to occur among girls who are poor, have low levels of education, and live in rural areas [3]. This condition limits the opportunities for women to get education and build life skills, separates them from family and friends, decreases the ability to make decisions on reproductive health issues and to seek appropriate care, and increases their vulnerability to health problems [4].

The phenomenon of early marriage, which has different levels of acceptance, implies that each society has diverse factors in viewing the phenomenon of early marriage. BKKBN (2012) states that the main root of the problems of early marriage in several provinces in Indonesia are generally caused by several dimensions including modernization, education, economic pressure and social culture [5]. A research in Bangladesh states that the determinants that influence early marriage include the education of respondents, the education of respondents' spouses, residential areas, spouses' jobs, religion, and the family size. The research shows that the level of religiosity influences marriage [4].

Early marriage can be associated with adverse consequences not only for teenage girls but also for the children they bear. High rates of unwanted pregnancy, abortion, premature labor, low birth weight babies, and fetal and maternal deaths were observed among teenage girls and were highly correlated with early marriage [3]. In addition, girls who get married in their teens are also affected psychologically and they are more likely to experience depression, anxiety, and other mood disorders [4]. They are especially at risk of physical and sexual violence in marriage [1].

The harmful effects of domestic violence on the health and welfare of women and children have been widely discussed in researches [5]. According to KR Jogja, out of 21 Subdistricts in the Regency of Magelang, the highest early marriage rate is in Pakis sub-district. The Magelang region government has made efforts to reduce the number of early marriages. The Community Empowerment, Women and Family Planning Agency (BPMPKB) Magelang City has made various efforts, some of which are conducting the socialization of early marriage and its impact in the village and city level, forming the OBAMA (community of Magelang kids) to accommodate youth activities with positive and beneficial activities therein. However, the existence of the activities has not been known by teenagers so that the number of early marriages in Magelang still cannot be suppressed. Therefore, it is necessary to study what factors affect early marriage and its impact in Pakis sub-district of Magelang regency. 


\section{METHOD}

This research is a qualitative type of research with a phenomenological approach. Data collection tools are recorders to record and the researchers themselves. The data collection is by interviewing in depth women who married in the early marriage age (less than 20 years) and the minimum marriage age of 1 year. Participants in this study were taken with a non-probability sampling technique with a snowball approach to women who experience early marriage in Pakis sub-district area which includes Ketundan Village, Banyusidi Village and Petung Village. The participants are as many as 8 people consisting of the main participants. For the triangulation process the participants are community leaders, namely the head of the KUA of Pakis sub-district, the Banyusidi Village Head and the Banyusidi Village Midwife. The research instrument is a list of interview questions about early marriage. The results of data collection were analysed using conventional content analysis.

\section{RESULTS AND DISCUSSION}

\subsection{Results}

Research conducted in three villages in Pakis District. The selection of participants using snowball techniques found 5 participants and 3 key persons with the following characteristics: age between 18-23 years, work as a housewife and farm labourer, age when got married 16-18 years, age of marriage 1-4 years, have no children, are pregnant and have one child, the husband's profession as a farm labourer and most are self-employed.

The results of this study indicate that there are two themes in this study, namely the causes of early marriage with six categories of determinants, namely economy, education, social culture, internal factors, parental roles; and the impact of early marriage on women's reproductive health in 3 categories, namely pregnancy, childbirth, postpartum.

The main factor that causes early marriage in this study is the economic factor. This is because parents do not have funds to pay for their children's schooling so they choose not to send their children to further education. These economic factors cause the teenagers' opportunity to continue education is reduced. Most of them only take 9 years of basic education. As stated by the following participant: "Actually education is important for my life ... but I deliberately did not continue the school because of costs or other ..." (participant 1).

Furthermore, teenagers look for work in big cities or become unemployed at home because job opportunities become limited to those with low levels of education. Data at the Office of Religious Affairs shows a different matter that there is an elementary school level of education in the data on early marriage in Pakis sub-district. According to the statement key person, "The factors that affect are level of education, which mostly are junior high school level. Those with high school education are rare" (Banyusid Village Head).
The jobs they obtain are such as shopkeepers or housemaids. They work only 1-3 years, then they choose to get married because of their own desires or asked by their parents to get married since in this area early marriage has become a culture of local residents. Parents will feel ashamed if their teenage daughters are not married because they will be considered as spinsters in the village. In addition, teenagers who have closeness with men before marriage will be considered as shameful behaviour and will be the subject of discussion by the villagers. It is as stated by the participant, "ee ... it's normal if a villager gets married early, because her age is enough and if no one asks to marry her, it will be a rumour to talk about by the villagers. Or if you look like you are riding with a man who is not yet your husband, then it will be discussed as a bad and shameful thing, so you should just get married .. this is not like in the city. In the village a girl will be considered a spinster if not married ". (Participant 2) In accordance with key person's statement that "For socio-culture, it is because riding motorbike with man is considered negative that the villagers will gossip so the parents marry their children" (Midwife Banyusid Village I).

Early marriage is also the willingness of young people themselves as stated by a participant, "Married at a young age is the desire of myself because in my mind I'll be happy because there will be someone who thinks of my needs, someone to find me the money for everyday needs" (Participant 3). The role of parents is very significant in making decisions related to early marriage practices, their decisions are influenced by the local social culture and economic factors in their families. Culturally, they tend to follow the orders of their parents. "Basically, I will just follow what my parents say. If I am asked to get married, I will definitely follow what my parents say. "(Participant 5). The impact of early marriage on reproduction health includes the effects on the conditions of pregnancy, childbirth, postpartum and in the management of children. During pregnancy participants experience unpleasant complaints. These complaints include nausea and severe vomiting during early pregnancy, swelling in the legs and feeling weight changes that make them less confident. "in my early pregnancy, I felt sick. the vomiting continued until more than 3 months, so my weight did not gain" (Participant 4). "Right at the beginning of pregnancy only vomit, then at the end of pregnancy all of the feet are swollen" (Participant 2). In addition, there is also a lack of nutrients during pregnancy that causing anaemia and chronic energy shortages.

The impact of early marriage on reproductive health during labour is the difficulty of labour, namely premature rupture of membranes, low birth weight babies, long deliveries, hydramnios; narrow pelvis so that labour cannot be normal, and it should be referred at the hospital. As stated by the following participant, "In the village it is called twin water ... there is a lot of water coming out just before delivery". (Participant 4). "Young women usually have narrow pelvis. When the age is less than 20 mostly the pelvis is still narrow, so the labour should be by Sectio Caesaria " (Midwife). The impact on postpartum problems is more on the problem of lactation that many young mothers experience problems in terms of lactation that they feel like lack of milk, so they do not implement exclusive breastfeeding. Besides, the 
young mothers also lack of understanding on how to care for their babies. As stated by participants, "I was like other mothers, at the beginning, my milk was a little ... it confused me. I also did not finish 6 months of breast milk " (Participant 2). " Sometimes because they are still young, so sometimes they do not painstakingly breastfeed, so that they fail exclusive breastfeeding " (Midwife).

\subsection{Discussion}

Factors causing early marriage are economy, education, socio-culture, internal factors, and parents' roles. The results of the study are in line with research conducted by Wulandari \& Sarwoprasodjo, which indicates that there is a relationship between economic statuses and early marriage. According to this study, there is a relationship of economic status with early marriage. People from families with low economic status tend to get married early more than those from family with high economic status. The factor causing early marriage is an economic factor, where the perpetrators of early marriage have an economy that is below average or classified as low. In line with other studies that show that a low family economy does not guarantee continuation of children's education so that a child who has completed primary education does not continue to higher education and only stays at home. The reason of early marriage is to ease the burden of parents and because of economic limitations and therefore cannot go to school anymore [6].

All of the participant state that education is really important and the early marriage they undertake make them feel they could no longer get further education. This is in line with research in Indonesia which shows that there is a complex relationship between child age marriage and education in Indonesia. Lower educational level related to the prevalence of marriage of children-age couples is higher. Improving educational achievement will reduce children marriage. Completion of junior high school education (SMP) causes a decrease in the prevalence of early marriage. The research obtains data that higher education encourages marriage to older age. This is caused by the increasing access and support for education [5]. The relationship between early marriage and education level is strengthened by several theories put forward by several researchers. Delprato states that early marriage is caused by not being able to continue their education to a higher level. That is caused by family economic weakness. Lack of ability to continue education makes them drop out of school. Other research results suggest that poor access to education for girls contributes to the high early marriage [2]. Girls who graduate from elementary and middle school are the biggest contributors to child marriage. Research by Eny states that education becomes factors and motifs that cause early marriage. Her research shows that early marriage occurs at the elementary school level [7]. Early marriage prevents women from getting a proper education, accessing employment and training opportunities, developing social relationships with peers, and participating in civilian life [8]. The education factor is one of the causes of early marriage. The education factor is one of the causes of early marriage. The low level of education encourages promiscuity because people have a lot of free time at the same time they should be at school. The amount of free time available they use in general to get along that leads to promiscuity beyond control, which results in many cases of premarital pregnancy so that they are forced to be married even though they are very young. The role of parents in early marriage is very closely related. Parents can be decision makers related to the implementation of early marriage. Besides that, parents who worry about their children going out too closely with the opposite sex, will immediately act decisively by marrying off their children regardless of the background of one's both psychological and biological maturity. In addition to the parent factor, there are factors that indeed originate from the children themselves, this is recognized by the participants that indeed they are the ones who want or are willing to get married early because they do not want coercion from parents. It is also related to social culture because according to participants, early marriage has become a common thing in the area. This result is supported by Adedokum's research that factors such as individual and contextual factors encourage them to get married early [9].

The high number of child marriage shows that the empowerment of law enforcement in marital law is still low. This is because there are still opportunities to legalize the marriage, although the minimum age rules for the bride and groom are set but if there is a marriage dispensation application adopted then it raises the opportunity for the family to continue to carry out the marriage and legalized by the relevant officials. The practice of early marriage is often influenced by local traditions. Even though there is a law stipulation that prohibits early marriage, there are also dispensation facilities. The Religious Courts and the Office of Religious Affairs (KUA) often provide dispensation if the bride is still underage. In Indonesia, the practice of underage marriage is common. The Marriage Law from 1974 also does not expressly prohibit the practice. The Marriage Law regulates the age limit for a person to be able to get married, which for men is 19 (nineteen) years and for women 16 (sixteen) years, but in the provisions of the law, there are deviations from the age requirement for marriage that can be requested by both male and female parents to submit a request for dispensation to the court or another official. This clearly gives an opportunity in the ratification of this marriage by KUA if marriage dispensation is requested by both parties who will carry out the marriage. Early marriage will also have implications for the backwardness of knowledge hamper the marriage due to the educational process. Socio-cultural aspects of the community have an influence on the implementation of marriage and cannot be separated also at this early marriage [10].

Early marriage gives a greater risk among girls in particular on the aspects of reproduction health. Things that need attention in early marriage are complications that occur during pregnancy and childbirth that can cause the child to be born at risk, as well as an increase in maternal and infant mortality. According to a research, $99.2 \%$ and $95.5 \%$ of women in Iran in 2017 received prenatal and postpartum health care, respectively. In addition, the rate of caesarean section is $30,25 \%$ among rural women. The contraceptive pill is the best-known method of birth control $(88,9 \%)$, 
Perspectives in Iranian Setting: A Qualitative Study,” J. Environ. Public Health, vol. 2016, p. 8, 2016. (28.5\%). Moreover, 59, $8 \%$ of rural women get married at age $\leq 18$ years. Sexually transmitted diseases which are most known for these women is HIV / $\operatorname{AIDS}(81,7 \%)$, and just over half have an experience of leucorrhoea during the past 12 months $(56.8 \%)$. Furthermore, these women have reported $33.1 \%$ of domestic violence in the past year [11]. Age when got married, current age, level of education, and household decision significantly influence $(\mathrm{P}<0.005)$ maternal health risks in the study area. This study determined that respondents in the 15-19 age group was 1,234 times more likely to experience complications when compared to the 20-24 year reference category. Rights and freedoms that are highly relevant for reducing maternal mortality, provided by international treaties are not accessible to young women in the study area [12]. Early marriage compared to adult marriage seems to be significantly related to lower age at first birth, higher fertility, increased risk of child death, reduced risk of contraceptive use before delivery, higher risk of giving birth three or more times, increased risk of pregnancy not, increase the risk of termination of pregnancy, and a higher risk of the recently used contraception method.

\section{CONCLUSION}

The study found that early marriage practices in Pakis subdistrict which included three villages where the research was based on various factors underlying the practice of early marriage, namely economic factor, education factor, social-cultural factor, internal factors, and parental roles factor, and had a direct impact on women's reproductive health, especially during pregnancy, giving birth until after giving birth, which affects the degree of health.

\section{ACKNOWLEDGMENT}

Our gratitude goes to the Research and Community Service Institute of the University of Muhammadiyah Magelang for the financial support and facilities provided, and to student Nur Aini Ambarwati for her contribution in the research process.

\section{AUTHOR CONTRIBUTIONS}

Conceptualization (R, R.M); Material research preparation (R); Methodology (R, R.M); Data collecting (R, N.A); Data analysis and visualization (R, R.M); Writing - original draft (R); Presentation (R).

\section{REFERENCES}

[1] S. Montazeri, M. Gharacheh, N. Mohammadi, J. Alaghband Rad, and H. Eftekhar Ardabili, "Determinants of Early Marriage from Married Girls'
[2] M. Delprato, K. Akyeampong, R. Sabates, and J. Hernandez-Fernandez, "On the impact of early marriage on schooling outcomes in Sub-Saharan Africa and South West Asia," Int. J. Educ. Dev., vol. 44, pp. 42-55, 2015.

[3] S. K. Mahato, "Causes and Consequences of Child Marriage: A Perspective,” Int. J. Sci. Eng. Res., vol. 7, no. 7, pp. 698-702, 2016.

[4] K. Sekine and M. E. Hodgkin, "Effect of child marriage on girls' school dropout in Nepal: Analysis of data from the Multiple Indicator Cluster Survey 2014," PLoS One, vol. 12, no. 7, pp. 1-13, 2017.

[5] Badan Pusat Statistik Indonesia, "Kemajuan yang Tertunda: Analisis Data Perkawinan Usia Anak di Indonesia," Jakarta, 2010.

[6] W. and S. Sarwoprasodjo, "Pengaruh Status Ekonomi Keluarga Terhadap Motif Menikah Dini Di Perdesaan," Sodality J. Sosiol. Pedesaan, vol. 2, no. 1, pp. 53-62, 2015.

[7] E. Widyawati and A. Pierawan, Cilik, "Determinan usia pernikahan dini di Indonesia," socia, vol. 14, no. 4, pp. 55-70, 2017.

[8] A. A. Marphatia, G. S. Ambale, and A. M. Reid, "Women's Marriage Age Matters for Public Health: A Review of the Broader Health and Social Implications in South Asia," Front. Public Heal., vol. 5, no. October, pp. 1-23, 2017.

[9] S. Montazeri, M. Gharacheh, N. Mohammadi, J. Alaghband Rad, and H. Eftekhar Ardabili, "Determinants of Early Marriage from Married Girls' Perspectives in Iranian Setting: A Qualitative Study," J. Environ. Public Health, vol. 2016, pp. 1-8, 2016.

[10] BPS, BKKBN, and Kemenkes, "Sdki," Survei Demogr. dan Kesehat. Indones., p. 266, 2013.

[11] M. N. Khosheh Khaleghinezhad1, Nourossadat Kariman2, Fatemeh Nahidi2, Abbas Ebadi3, "Electronic Physician," Electron. Physician, vol. 10, no. 4, pp. 6640-6646, 2018.

[12] O. Adedokun, O. Adeyemi, and C. Dauda, "Child marriage and maternal health risks among young mothers in Gombi, Adamawa state, Nigeria: Implications for mortality, entitlements and freedoms," Afr. Health Sci., vol. 16, no. 4, pp. 986-999, 2016. 